\title{
REGIONAL COLITIS
}

\section{A Review and a Report of a Case Presenting as a Surgical Emergency}

\author{
By C. L. Clinton-Thomas, F.R.C.S. \\ Surgical Specialist, Federation of Malaya
}

Regional (or segmental) colitis has been defined (Neuman et al. I 954) as ' an inflammatory disease of unknown aetiology involving initially one or more segments of the large intestine, exclusive of the rectum and rectosigmoid, either as a continuous lesion or as multiple discontinuous lesions ': and is said to constitute 4 to $10^{\circ}$ per cent. of all cases of chronic ulcerative colitis (Bargen, I 943).

Since the early part of this century when inflammatory tumours of the large bowel of unknown origin were reported by several authors (Moynihan,..1907; Mayo Robson, 1908; Tietze, I920; Moschowitz and Wilensky, I923) and Dalziel (1913) described the lesions of the terminal ileum which are now associated with the name of Crohn (Crohn, Ginsburg and Oppenheimer, I932) a considerable, and sometimes confusing, body of literature has accumulated on the subject of the non-specific granulomata of the large and small intestine.

Granulomatous lesions affecting isolated segments of the colon, with or without subsequent involvement of either the terminal ileum or rectosigmoid or both and variously described as examples of regional migratory chronic ulcerative colitis, right-sided regional colitis, regional enterocolitis and regional or segmental colitis have been the subject of papers or references have been made to lesions of this type in papers on Crohn's disease or chronic ulcerative colitis.

The disease is usually chronic in nature, and in a recent study of a large series of cases from the Mayo Clinic (Neuman et al. 1954) the average duration of symptoms prior to the first examination was 3.6 years. No mention is made of any patient having been first seen as an acute abdominal emergency. It follows, therefore, that patients for whom surgical treatment was considered necessary were subjected to planned operations only after careful preliminary investigations had made the diagnosis reasonably certain.

Brownlee (I95I), reporting three cases of regional colitis that had first presented as surgical emergencies, drew attention to an uncommon variety of this disease which has had little recogni- tion in the literature of emergency abdominal surgery. He discussed the treatment and showed that although a pre-operative diagnosis was almost impossible, knowledge of the condition should at least enable a provisional diagnosis to be made at laparotomy.

Failure to recognise the lesion or to be aware of its possibility may result in a decision for ' masterly inactivity' with consequent embarrassment for the surgeon and increased risk and anxiety for the patient. This is shown in the case reported by Thompson (1950), in which two laparotomies were done before the true nature of the condition was revealed by a barium enema.

The case to be reported is another example of this uncommon disease manifesting itself for theo first time in an acute form.

\section{Case Report}

F.G.R.W., a retired bus driver, aged $7 \mathrm{I}$ years, was admitted to hospital on March 26, I95I, complaining of abdominal pain, nausea and vomiting.

History. The abdominal pain was of sudden onset nine hours before admission, colicky in nature and situated in the epigastrium. For the previous four days he had been feeling unwell with loss of appetite and slight fever. $\mathrm{He}$ had been constipated for three days.

Past history. He stated that he had been in excellent health until three months previously when he began to get attacks of constipation lasting from two to four days with occasional diarrhoea between these periods. No blood or mucus had been seen in the stools. His appetite had remained good and he had been gaining slightly in weight.

On examination. He was a pale, thin, elderly man in obvious pain. His temperature was normal and the pulse rate was slightly increased. His tongue was dry and furred and his breath foul. The abdomen was slightly distended and tender to palpation all over with some guarding of the upper quadrants. Bowel sounds were audible but infrequent. 
On rectal examination there was slight tenderness in the recto-vesical pouch. A radiograph of the abdomen did not show any evidence of intestinal obstruction. A white cell count was normal. An enema produced a good result; some blood and mucus being noticed in the stool. Following the enema there was a considerable improvement in his condition.

Two hours later the abdominal pain returned with increased frequency and severity and he vomited copiously.

A tentative diagnosis of intestinal obstruction was made and it was decided to do an exploratory laparotomy.

Continuous gastric suction and an intravenous drip were started.

First operation. Under general anaesthesia the abdomen was opened through a right paramedian para-umbilical incision. There was a small amount of soapy, non-odorous, exudate in the peritoneal cavity. The right colon and caecum were slightly distended and the proximal part of the descending colon, for a distance of approximately 4 in., was dilated, thickened and acutely inflamed; the serosa was bright red in colour. The affected segment was fairly sharply demarcated from the bowel on either side which appeared to be quite normal, as was the parietal peritoneum and lymphatic field draining the area. The greater omentum was firmly adherent in one part and the whole mass appeared to be fixed posteriorly. The remainder of the abdominal viscera were normal in appearance.

It was thought that the lesion in the colon might be due to a perforation of unknown aetiology that had become sealed off, an isolated area of diverticulitis, or an acute segmental colitis.

Owing to the fixation of the mass and the fear of disturbing omental adhesions exteriorisation was not attempted.

The patient's condition was somewhat unsatisfactory and primary resection was not considered.

A valvular caecostomy was done through a grid-iron incision and the abdomen closed.

Post-operative. Despite gastric suction and intravenous fluids he developed a paralytic ileus with gross distension, which was relieved by the passage of a Miller-Abbot tube. The caecostomy did not begin to function properly until the fifth day.

One week later he had an attack of severe pain in the chest, accompanied by cough and dyspnoea, and was thought to have had a pulmonary embolus, although there was no evidence of phlebothrombosis in the calf veins. At no time was the sputum blood-stained and a radiograph of the chest was normal in appearance. Intravenous heparin was given for five days.

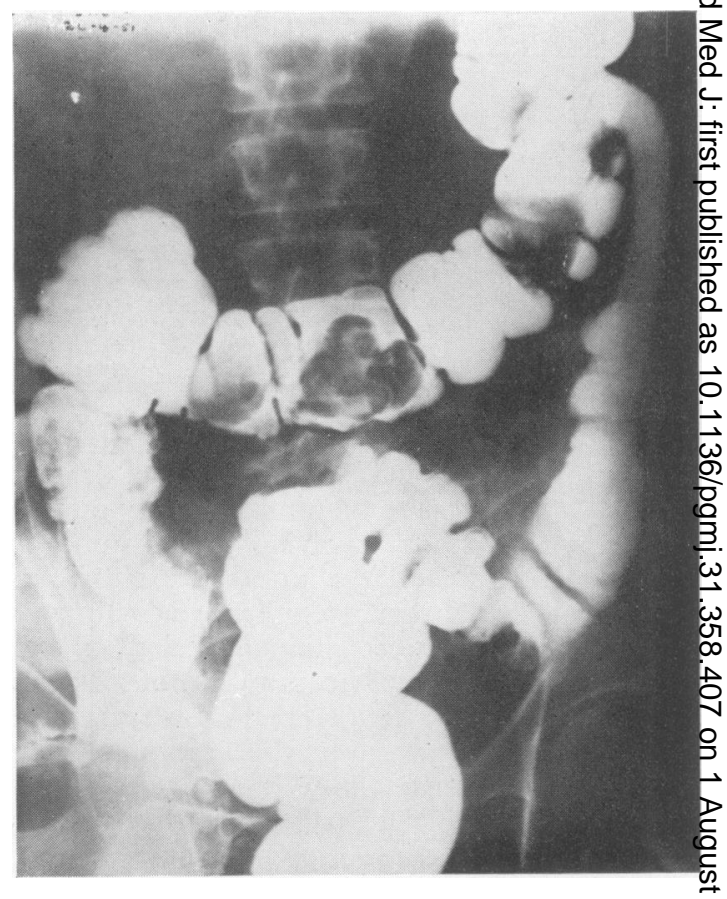

FIG. I.-Barium enema nine days after admission shov $\overrightarrow{0}$ ing loss of haustrations in the proximal part of the descending colon.

He was well enough to have a barium enema:or? April 4, I95 I, which was reported on as follows

' No obstruction to barium flow. The proximad half of the descending colon is narrowed. The appearance does not suggest neoplasm but this. cannot be excluded. It looks more like ar inflammatory lesion. ? Area of colitis.' (Fig. I)

On June 6, 195 I, he was sent to a convalescen home for three weeks and on his return looked. extremely well. He stated that he had not passeg flatus or faeces per rectum.

A second barium enema was done on June 28 and was reported on as follows:

'The area of colon now appears very narrow without any marked obstruction to the barium flow. It looks like a Crohn's lesion now (Fig. 2).

Sigmoidoscopy showed no abnormality of the rectum or rectosigmoid and repeated examination of faeces from the caecostomy failed to reveal evidence of Enantamoebae histolytica or othei pathogenic organisms.

The Wasserman reaction was negative.

It was decided to excise the diseased segmento

Second operation. On July 7, 1951, following routine preparation of the bowel with chemotherapy, the abdomen was reopened through ab5 upper left paramedian incision. The proxima half of the descending colon was markedlo 


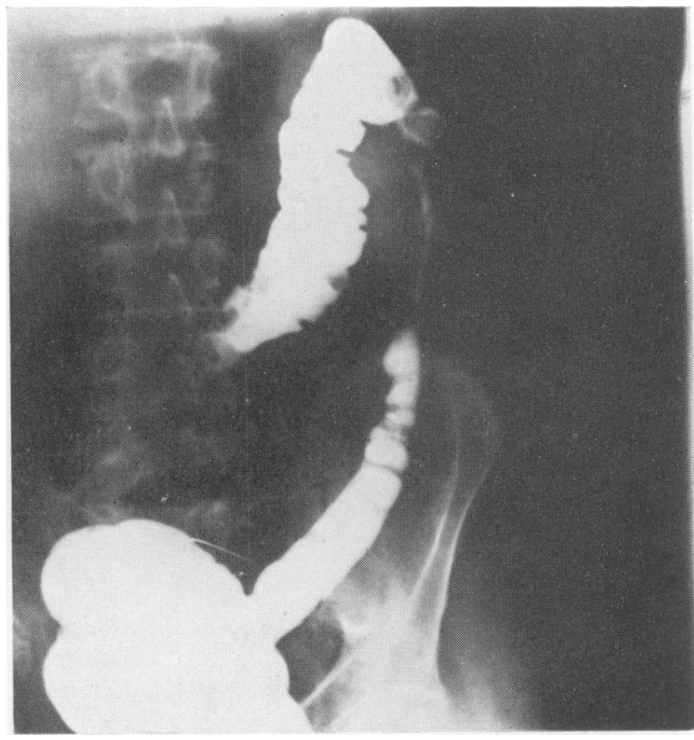

FIG. 2.-Barium enema two months later showing a long 'string' stricture of the proximal descending colon.

narrowed in diameter and the walls were grossly thickened. The remainder of the large and small intestine still appeared to be quite normal. A small part of the transverse colon and the descending colon, as far as the first sigmoid artery, were resected and an end-to-end anastomosis done with interrupted silk in two layers.

Post-operative progress. Recovery from this operation was quite uneventful. Faeces were passed per rectum on the third day. The caecostomy was closed ten days later and two weeks afterwards he was discharged from hospital.

Since then he has been free from symptoms any repeated barium enemas have not shown and evidence of recurrence. When last seen in January I955, nearly four years later, he was fit and well despite his age.

\section{Report on the specimen:}

An $18 \mathrm{~cm}$. segment of colon was received. Unfortunately it has been slit open before fixation with the result that retraction during fixation rendered satisfactory photography impossible.

The segment is much narrowed, apart from the terminal $\mathrm{I}$ to $2 \mathrm{~cm}$. at each end. The whole wall is thickened and shows linear, depressed, smooth scarring and ulceration of the mucosa.

On section the 'hypertrophy' is seen to affect mainly the submuscosa and the muscular coats. The outer longitudinal muscle layer is thickened by the presence of a true increase in muscle tissue, there being abrupt transition from this to the adjacent normal tissue, where the majority of the muscle bundles of the affected tissue can be seen to end.

The inner circular muscle layer is also hypertrophied although here oedema also plays a part. The plexus of nerves and ganglion cells lying between these layers seems bulkier and more evident in the affected zone than in the adjacent normal tissue, but this is a point of doubtful significance.

The submucosa shows fibrous tissue increase and moderate, mainly perivascular round cell, plasma cell and eosinophil infiltration. Areas of ulceration of the mucosa are present. The changes here are those generally associated with subacute infections and present no specific alterations. Giant cells were not seen although several sections were searched.

The picture verifies the clinical diagnosis of regional colitis. (Figs. 3, 4, 5).

\section{Discussion}

Crohn originally thought that the lesions which he had described in the terminal ileum were an entity distinct from the granulomata known to occur in the large intestine but later (Crohn and Rosenak, 1936) he reported nine cases of combined

ileitis and colitis.
Ulcerative colitis of regional type was firs described by Bargen and Weber (1930). Crohn and Berg (1938) reported similar cases and usedP. the term right-sided (regional) colitis because of their observation (since disproved) that the disease always began in the right side of the colon.

Since then Bargen and Crohn, in association with others, have made important contributions to the study of regional colitis in a series of papers (Barbosa, Bargen and Dixon, I945; Crohn, Garlock and Yarnis, 1947; Neuman, Bargen and Judd, I954).

In the last of these papers, 201 cases were reviewed.

Although no age was exempt, the greatest incidence of the disease was in the third decade. There was no significant difference in sex incidence. The most frequent symptoms were diarrhoea, often with manifest blood, loss of weight, griping abdominal pain and fever. The most common findings on physical examination were evidence of wasting, anaemia and abdominal tenderness. Peri-anal and peri-rectal complications were found in 13.5 per cent. of patients at the first examination.

The transverse colon was involved most frequently and the right colon more often than the left. Subsequent spread to the terminal ileum was noted in 22 per cent. of patients; the rectum and rectosigmoid were eventually involved even more frequently. While inflammatory 


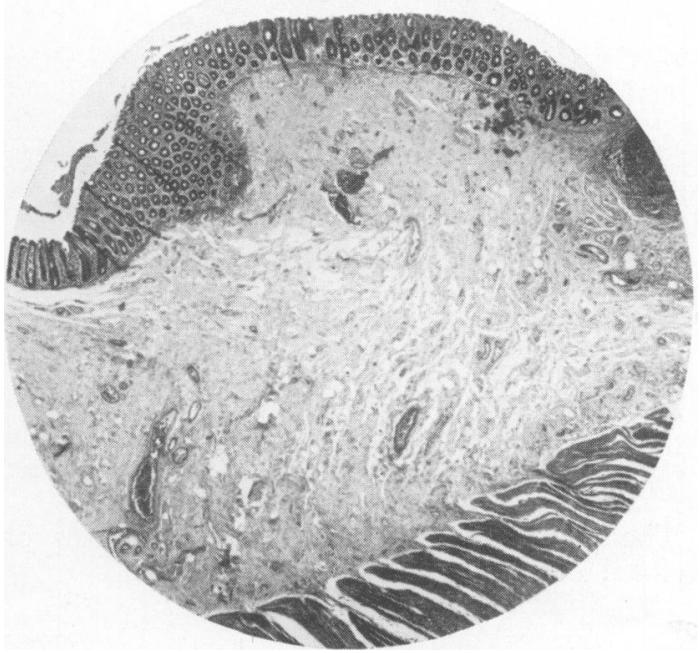

Fig. 3.-H. \& E. $\times$ I5. Section of affected colon showing mucosa, submucosa and part of muscle layer. There is no muscularis mucosae and the submucous layer is greatly thickened by fibrous tissue.

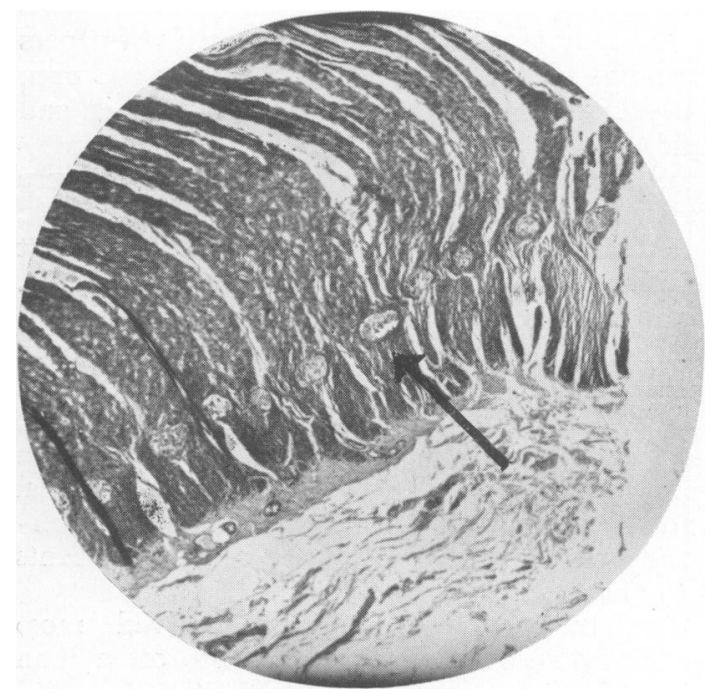

FIg. 5.-H. \& E. $\times$ 25. Section of affected colon showing muscle and serosa. The prominent myenteric nerve plexus can be seen between the muscle layers.

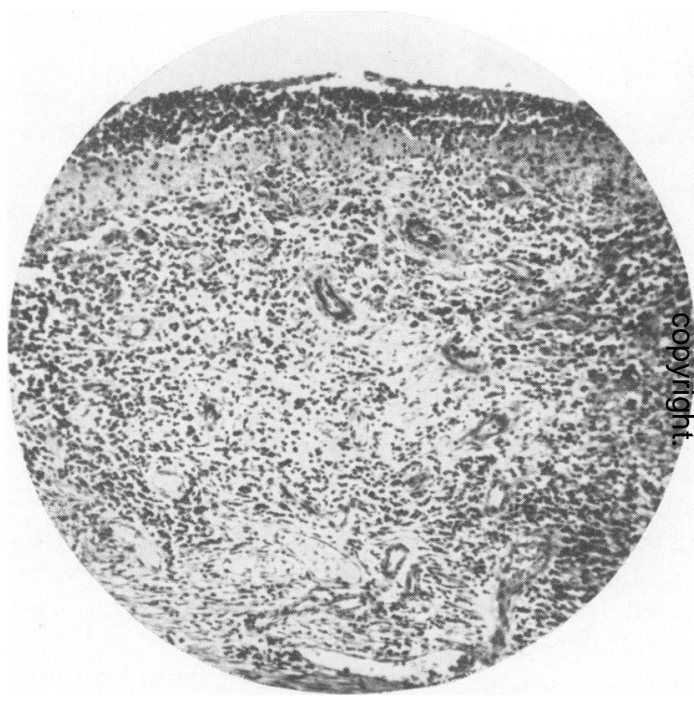

FIG. 4.-H. \& E. $\times$ 95. Section of affected color showing mucosa and submucosa. The epithelium is denuded and the submucosa shows subacute. inflammatory changes. Giant cells are simulatec5 by some of the capillaries. 
polypoid hyperplasia of the mucosa in the affected segment of intestine was very common, malignant change was not seen.

Neuman and Dockerty (1954) have described the pathological findings in this series. The predominant gross features were ulceration of the mucous membrane and thickening of the intestinal wall. Microscopically the lesion consisted of a non-specific subacute and chronic granulomatous inflammatory process involving the entire thickness of the bowel. It was exceptional for the lesion to extend more than $3 \mathrm{~cm}$. beyond the gross limits of disease.

They suggested that the earliest lesion might have been a purulent cryptitis followed by microscopic abscess formation and ulceration of the overlying mucosa.

Their observations are in general agreement with those of Lumb (195I) who came to the conclusion that the syndromes variously known as regional ileitis, regional entero-colitis, regional colitis and chronic ulcerative colitis did not exist as separate entities so much as varieties of an essentially similar process manifesting itself in different areas of the bowel from case to case.

This view is supported by cases in which regional ileitis and ulcerative colitis have either followed one another or were coincidental. (Leading article the Lancet, May, 1948.)

Interesting as these pathological findings are they do not elucidate the problem of treatment of these various diseases.

Wells (1952) recognized that the lesions were microscopically identical but suggested a grouping of cases on the basis of descriptive pathology. For practical purposes he defined three separate entities: chronic idiopathic ulcerative colitis, Crohn's disease and segmental colitis. He considered that the last was probably a variant of regional ileitis and that it had absolutely no relationship to ulcerative colitis. He contrasted the thickened, tough and fibrous bowel seen in the colonic lesions of Crohn's disease and regional colitis with the oedematous and friable bowel found in ulcerative colitis. He also pointed out that while sinus formation, adhesions and 'skip' lesions were conspicuous by their absence in the last disease they were not uncommon in the first two. Of similar interest is the contrast between the frequent occurrence of malignant change, arthritis, iritis and skin lesions in ulcerative colitis and their absence in the other two conditions.

\section{Treatment}

Apparently complete and permanent recovery of bowel affected by regional colitis may follow medical treatment, consisting of rest in bed, dieting and antibiotics, but recurrence is so frequent-in nearly two-thirds of the Mayo Clinic series-that a strong case can be made for surgical intervention.

Corbett (1945) states that regional colitis confined to the left colon is a firm indication for temporary transverse colostomy, which should in all cases be followed by a local resection.

Wells (1952) and Butler (1953) also consider that resection with end-to-end anastomosis or short circuiting with exclusion, with or without subsequent resection, is the correct treatment for regional colitis.

Neuman et al. (1954) found that the recurrence rate was almost halved by resection or shortcircuiting of the diseased segment; the incidence of post-operative complications being considerably less after the latter procedure although the recurrence rate was no greater. However, spread may occur by direct extension in the mucosa and submucosa, and today, when antibiotics and chemotherapy are available, it seems reasonable to excise the affected segment rather than by-pass it.

So few cases of regional colitis, first presenting as acute abdominal emergencies, have been reported that there must be some doubt regarding the correct initial treatment in this type.

In the case reported here the history of constipation with occasional attacks of diarrhoea before the sudden onset of acute symptoms suggests that an acute process, probably infective, attacked a segment of bowel already the seat of chronic disease. This is probably the course of events in most cases of acute regional colitis and must have a bearing on treatment.

Other important factors influencing the choice of procedure to be adopted are, firstly the impossibility of making any more than a tentative diagnosis at the exploratory laparotomy and secondly, even if the diagnosis is correct, the difficulty in judging how the acute lesion will behave.

A prominent and surprising feature of the case reported in this paper was the rapidity with which the affected segment of bowel became stenosed. Stricture formation is noticeable in most of the recorded cases and may well be characteristic of the acute form of regional colitis.

Is there a place for conservative treatment ? Brownlee (195I) thought that further experience might possibly show that there was for the early acute lesion. He did not state how this was to be recognised and he based his supposition on an analogy with Crohn's own typing of regional ileitis (Crohn, Ginsberg and Oppenheimer, I933) and the results of conservative treatment of the early acute lesion in that disease. 
There is, however, some uncertainty as to what constitutes the early acute phase of Crohn's disease. Armitage and Wilson (1950) were of the opinion that the 'acute terminal ileitis,' of sudden onset occasionally encountered during operations for supposed acute appendicitis, and which in their experience resolved without treatment and never recurred, had no relation to the acute type of Crohn's disease.

In the latter disease, while the presenting signs and symptoms might be indistinguishable, there was almost invariably a history dating back months and perhaps years of vague abdominal discomfort, colicky pain and diarrhoea.

Resolution, in their experience, did not usually occur in these cases and resection or shortcircuiting was necessary.

It is possible that there is an acute segmental colitis comparable to the benign type of "acute terminal ileitis.' In one of Brownlee's cases complete resolution appeared to have taken place by the time a radiological examination was carried out.

However, if the signs and symptoms have been sufficiently serious to warrant laparotomy it seems wise to divert the faeces.

Primary resection cannot be justified and exteriorisation, while theoretically attractive, is likely to be difficult owing to pericolitis and adhesions.

For the usual case a transverse colostomy or a caecostomy, depending on the site of the lesion, is probably the procedure of choice in the first place.

Brownlee (195I) drew attention to the difficulty in estimating the extent of the acute lesion at laparotomy and in one of his cases a ' skip ' lesion in the distal colon escaped notice and was only demonstrated by a post-operative barium enema.

He advocated transverse colostomy, with complete division of the bowel, provided that it would not interfere with a resection if that subsequently became necessary. If there was likely to be insufficient normal bowel between a colostomy and the diseased segment he preferred a preliminary ileostomy for the acute type in which he considered complete faecal diversion to be necessary, or a caecostomy for the more slowly progressive lesion of the obstructive type. Further treatment, either restitution of intestinal continuity or resection depended on whether or not the bowel was permanently damaged as shown by the persistence of signs and symptoms and barium enema radiography.

It seems doubtful if lesions with such clearly defined differences in behaviour could be identified with certainty and in the case reported here features of both types were in evidence.
A caecostomy proved satisfactory, althoug there is a possibility that the colitis might have resolved if the faeces had been completely diverted.:

It did not interfere with the resection tha subsequently became necessary; its final closure was a simple procedure compared to that whick would have been required to restore intestinal continuity after a defunctioning ileostomy and provided a safety valve following anastomosis

Antibiotics and chemotherapy have, however, made this precaution unnecessary in most cases and a transverse colostomy would probably have been preferable.

The closure of the colostomy and its freeing from the abdominal wall could have been done. immediately prior to the resection, thus avoiding any hindrance its presence might have had oin that procedure.

To summarise it is suggested that a transvers $\ddot{E}$ colostomy should be done for acute segmental colitis in the descending colon and it is probably the most suitable emergency measure for acut $\vec{e}$ lesions involving the splenic flexure and the distat part of the transverse colon. A caecostom appears to be the best emergency operation for acute lesions in the proximal transverse colong hepatic flexure and distal ascending colon, whele an ileo-transverse colostomy would be indicated for acute regional colitis in the caecum and proxis mal ascending colon. Acute colitis involving this last site and necessitating an emergency operation has not yet been reported. In most of the recorded cases the lesion has been found in the transverse colon or near the flexures buf this is probably coincidental.

A careful radiological examination of the bowet if necessary repeated, should follow as soon as the patient is well enough. It is largely on the evidence that the diagnosis will be confirmed and a decision made as to whether or not the affecteä. intestine should be excised. Tuberculoma ang amoeboma, particularly if there has been residence in an endemic area, should, as far as possible, be excluded by radiography of the chest, sigmoido scopy and microscopic examination of the faeces Other less common causes of granulomata in the colon are syphilis and actinomycosis. Endometrp osis may also produce obstructive lesions leading to errors in diagnosis.

With positive radiological findings both carg cinoma and localized diverticulitis would have to be considered in the differential diagnosis. The recognition of these diseases does not usuall present any difficulty. In any event resection would be indicated and it is only by pathologica examination of the excised bowel that a certai diagnosis can be made.- 


\section{Prognosis}

While the immediate results of resection in acute regional colitis appear to be good, few cases have been reported and none has had a long follow up. In the case reported here and the one described by Thompson (personal communication) there has been no evidence of recurrence after four and five years respectively. In chronic regional colitis, recurrence following excision or short circuiting is unfortunately by no means uncommon. Neuman et al. (1954), record a recurrence rate of 37 per cent. after surgical procedures but they point out that their figures are based on a small number of cases and that the follow up has been short in most. Relapse after a long interval of apparent cure is not unknown and Butler (1953) records a case in which this occurred after eight years.

\section{Summary}

A case of regional colitis, which first presented as an acute abdominal emergency, is reported. Following a caecostomy the affected segment of bowel rapidly stenosed and was subsequently resected. A four year follow-up shows no evidence of recurrence.

The literature is reviewed and the pathology and treatment are discussed.

I wish to thank Mr. J. A. McLauchlan, under whose care the patient was admitted, for permis- sion to publish this case; Dr. T. Culoty for the radiological reports; and Dr. L. Steingold for the pathological report.

I am indebted to Dr. Lynne Reid and the Photographic Department of the Brompton Hospital for the photomicrography.

\section{BIBLIOGRAPHY}

ARMITAGE, G., and WILSON, M. (1950), Brit. F. Surg., 38, 182. BARBOSA, J. DE C., BARGEN, J. A., and DIXON, C. F. (1945), Surg. Clin. N. Amer., 25, 939.

BARGEN, I A. (1943), 'The Modern Management of Colitis,' C. C.'Thomas, Springfield, Ill.

BARGEN, J. A., and WEBER, H. M. (1930), Surg. Gyn. Obst., 50, 964 .

BROWNLEE, T. J. (195I), Brit. F. Surg., 38, 507

BUTLER, E. C. B. (1953), Proc. Roy. Soc. Med., 46, 69.

CORBETT, R. S. (1945), Ibid., 38, 277.

CROHN, B. B., and BERG, A. A. (1938), F. Amer. med. Ass., I10, 32.

CROHN, B. B., GARLOCK, J. H., and YARNIS, H. (1947), Ibid., 134, 334 .

CROHN, B. B., GINSBERG, L., and OPPENHEIMER, G. D. (I932), Ibid., 99, 1323.

CROHN, B. B., and ROSENAK, B. B. (1936), Ibid., 136, I.

DALZIEL, T. K. (1913), Brit. med. F., i, 425.

LUMB, G. (1951), Brit. F. Surg., 39, 233.

MOSCHOWITZ, E., and WILENSKY, A. G. (1923), Amer. F. med. Sci., 166, 48 .

MOYNIHAN, B. G. A. (1907), Edin. med. f., 21, 228.

NEUMAN, H. W., BARGEN, J. A., and JUDD, E. S. (1954), Surg. Gyn. Obst., 99, 563.

NEUMAN, H. W., and DOCKERTY, M. B. (1954), Ibid., 99 572.

ROBSON, A. W. MAYO (1908), Brit. med. F., i, 425.

THOMPSON, H. R. (1950), Proc. Roy. Soc. Med., 43, 685.

TIETZE, A. (1920), Erg. Chir. Orthop., 12, 211.

WELLS, C. (1952), Ann. Roy. Coll. Surg. Eng., II, 105.

\section{NOTICE OF SPECIAL INTEREST TO SUBSCRIBERS:}

"WHY NOT HAVE YOUR COPIES OF THIS JOURNAL BOUND INTO YEARLY VOLUMES?"

Arrangements have now been made to have the twelve monthly issues fully bound in dark green pin head cloth, lettered in gilt on spine with name of Journal, Volume Number and year, complete with index at front, 17s. 6d. per Volume, post free. A limited number of out of print journals are available to bind into volumes and make your library complete. Price on application giving details of issues required to complete back volumes.

THE FELLOWSHIP OF POSTGRADUATE MEDICINE 60 PORTLAND PLACE, LONDON, W.I

\section{WHY NOT HAVE YOUR JOURNALS BOUND?}

Bibliography continued from page 402-M. H. M. Harrison, Ch.M., F.R.C.S.

\section{BIBLIOGRAPHY}

ADAMS, J. C. (1953), f. Bone ft. Surg., 35B, 199.

BATCHELOR, J. S. (1948), Postgrad. med. F., 24, 24 I.

CHARNLEY, J. (1953), 'Compression Arthrodesis.' E. and S. Livingstone, London.

DEVAS, M. S. (1954), f. Bone ft. Surg., 36B, 561.

HARRIS, R. (1955), Personal communication.

HARRISON, M. H. M., SCHAJOWICZ, F., and TRUETA, J(1953), $\mathfrak{f}$. Bone $\dot{f}_{t}$. Surg., 35B, 598.

JUDET, J., JUDET, R., LAGRANGE, J., and DUNOYER, I (I954), "Resection-reconstruction of the hip; arthroplasty with an acrylic prosthesis."
KOTTKE, F. J., KOZA, D. W., KUBICEK, W. G., and OLSON, M. (1949), Arch. phys. med., 30, 431.

McFARLAND, B., and OSBORNE, G. (1954), f. Bone ft. Surg., 36B, 364 .

McMURRAY, T. P. (1939), f. Bone $\mathfrak{f t}$. Surg., 21, I.

SCALES, J. (1954), Personal communication.

SCOTT, B. O. (1955), Personal Communication.

SHEPHERD, M. M. (7954), f. Bone ft. Surg., 36B, 567.

SMITH-PETERSEN, M. N. (1939), F. Bone ft. Surg., 21, 269.

TAYLOR, R. G. (1950), f. Bone ft. Surg., 32B, I6r. 